\title{
Crescimento de gramíneas e leguminosas forrageiras tropicais sob sombreamento
}

\author{
Carlos Mauricio Soares de Andrade ${ }^{(1)}$, Judson Ferreira Valentim ${ }^{(1)}$, Jailton da Costa Carneiro(2) \\ e Felipe Alexandre Vaz $^{(1)}$
}

\begin{abstract}
(1)Embrapa Acre, Caixa Postal 321, CEP 69908-970 Rio Branco, AC. E-mail: mauricio@cpafac.embrapa.br, judson@cpafac.embrapa.br, vaz@cpafac.embrapa.br (2)Embrapa Gado de Leite, Rua Eugênio do Nascimento, 610, Dom Bosco, CEP 36038-330 Juiz de Fora, MG. E-mail: jailton@cnpgl.embrapa.br
\end{abstract}

\begin{abstract}
Resumo - O objetivo deste trabalho foi avaliar o efeito de níveis de sombreamento artificial $(0 \%, 30 \%, 50 \%$ e $70 \%$ ) nas taxas de acúmulo de matéria seca de quatro gramíneas (Brachiaria brizantha cv. Marandu, B. humidicola cv. Quicuio-da-amazônia, Panicum maximum cv. Massai e Paspalum notatum cv. Pensacola) e três leguminosas forrageiras (Arachis pintoi cv. Belmonte, A. pintoi BRA-031143 e Pueraria phaseoloides), em Rio Branco, Acre. No período de novembro de 1999 a abril de 2001, foram realizados nove cortes para medição das taxas de acúmulo de matéria seca. Os capins marandu e massai tiveram o melhor desempenho entre as gramíneas, aliando boa tolerância ao sombreamento e alta capacidade produtiva, constituindo opções importantes na composição de sistemas silvipastoris em áreas com solos bem drenados. O quicuio-da-amazônia apresentou menor tolerância ao sombreamento, podendo ser usado em sistemas silvipastoris com baixa densidade arbórea, em áreas com chuvas bem distribuídas ou com solos mal drenados. O capim-pensacola apresentou alta tolerância ao sombreamento, mas baixa capacidade produtiva, não sendo recomendado para a região. O Arachis pintoi cv. Belmonte demonstrou maior capacidade produtiva e tolerância ao sombreamento que as demais leguminosas.
\end{abstract}

Termos para indexação: Amazônia Ocidental, estresse hídrico, luz, desempenho de cultura, sistema silvipastoril.

\section{Growth of tropical forage grasses and legumes under shade}

\begin{abstract}
The objective of this work was to evaluate the effect of levels of artificial shade $(0 \%, 30 \%, 50 \%$ and $70 \%$ ) on dry matter accumulation rates of four tropical forage grasses (Brachiaria brizantha cv. Marandu, B. humidicola cv. Quicuio-da-amazônia, Panicum maximum cv. Massai and Paspalum notatum cv. Pensacola) and three forage legumes (Arachis pintoi cv. Belmonte, A. pintoi BRA-031143 and Pueraria phaseoloides) in Rio Branco, Acre, Brazil. To measure dry matter accumulation rates, nine cuts were performed between November 1999 and April 2001. The grasses Marandu and Massai had the best performance, with good shade tolerance and productivity, and were good options for silvopastoral systems in areas with well-drained soils. The quicuio-daamazônia grass showed lower shade tolerance, and was recommended only for low tree density silvopastoral systems in areas with good rainfall distribution or with poorly drained soils. The Pensacola grass showed high shade tolerance but it is not recommended for silvopastoral systems in the Western Amazon region because of its low yield capacity. Arachis pintoi cv. Belmonte showed higher yield capacity and shade tolerance than the other legumes.
\end{abstract}

Index terms: Western Amazon, water stress, light, crop performance, silvopastoral systems.

\section{Introdução}

O desenvolvimento de sistemas de uso da terra mais diversificados e equilibrados, menos dependentes de insumos externos e com maior longevidade produtiva é uma necessidade na Amazônia. Na pecuária, principal atividade econômica rural na região, os sistemas silvipastoris têm potencial de substituir com vantagens os atuais ecossistemas de pastagens cultivadas, que em sua grande maioria são constituídos por monoculturas de gramíneas forrageiras, tornando a atividade ainda mais sustentável econômica e ambientalmente (Franke et al., 2001).

Um dos requisitos para o sucesso de sistemas silvipastoris sustentáveis é a escolha acertada das es- 
pécies componentes do sistema. No caso das espécies forrageiras, não basta que estas sejam tolerantes ao sombreamento, é necessário selecionar espécies com boa capacidade produtiva, adaptadas ao manejo e ambientadas às condições edafoclimáticas da região onde serão implantadas (Garcia \& Andrade, 2001).

A Brachiaria brizantha cv. Marandu é a gramínea forrageira mais plantada no Acre e uma das que têm obtido melhor desempenho sob sombreamento (Carvalho et al., 1997; Costa et al., 1998; Andrade et al., 2001b). Entretanto, sua baixa adaptação ao excesso de água no solo (Dias-Filho \& Carvalho, 2000) provoca a morte de touceiras, quando plantada em solos de baixa permeabilidade, predominantes no Acre, causando a degradação de milhares de hectares de pastagens (Valentim et al., 2000a). Em virtude de sua boa adaptação ao excesso de água no solo (Dias-Filho \& Carvalho, 2000), a B. humidicola cv. Quicuio-daamazônia tem sido muito plantada no Estado em substituição à $B$. brizantha $\mathrm{cv}$. Marandu. Entretanto, seu potencial em termos de uso em sistemas silvipastoris tem sido pouco estudado.

Várias cultivares de Panicum maximum têm sido testadas sob sombreamento, todas apresentando bom desempenho (Carvalho et al., 1997; Castro et al., 1999; Andrade et al., 2001a, 2001b). A cultivar Massai, lançada recentemente pela Embrapa Gado de Corte e recomendada para o Acre (Valentim et al., 2001a), ainda não foi testada sob sombreamento. Também o gênero Paspalum apresenta várias espécies com alta tolerância ao sombreamento (Wong, 1991), produzindo melhor na sombra das árvores do que a pleno sol (Wilson et al., 1990). O Paspalum atratum cv. Pojuca, gramínea forrageira de alta capacidade produtiva (Valentim et al., 2000b; Karia \& Andrade, 2001), tem demonstrado bom desempenho sob sombreamento natural na Amazônia Ocidental (Costa et al., 1998).

As leguminosas forrageiras são relevantes na produtividade das pastagens, incorporando $\mathrm{N}$ atmosférico ao sistema solo-planta e melhorando a alimentação do rebanho. No Acre, a Pueraria phaseoloides é utilizada com sucesso há anos, em mais de 30\% da área de pastagens cultivadas (Embrapa, 1999). É uma espécie que apresenta bom desempenho sob sombreamento, sendo utilizada como cultivo de cobertura do solo em plantações de seringueira e dendê, em toda a Região Amazônica. Outra leguminosa forrageira que vem sendo utilizada com sucesso em pastos consorciados no Acre é o Arachis pintoi cv. Belmonte (Valentim \& Moreira, 2001;
Valentim et al., 2001b). As leguminosas do gênero Arachis são consideradas tolerantes ao sombreamento (Johnson et al., 1994; Pizarro \& Rincón, 1994; Andrade \& Valentim, 1999).

O objetivo deste estudo foi avaliar o efeito de níveis crescentes de sombreamento artificial nas taxas de acúmulo de matéria seca de gramíneas e leguminosas, em Rio Branco, Acre.

\section{Material e Métodos}

Este estudo foi realizado no Campo Experimental da Embrapa Acre, em Rio Branco, AC. A região apresenta pluviosidade média de $1.900 \mathrm{~mm}$, com estação seca bem definida de julho a setembro, temperatura média de $25^{\circ} \mathrm{C}$ e $87 \%$ de umidade relativa do ar. Quatro gramíneas (Brachiaria brizantha cv. Marandu, B. humidicola cv. Quicuio-da-amazônia, Panicum maximum cv. Massai e Paspalum notatum cv. Pensacola) e três leguminosas forrageiras (Arachis pintoi cv. Belmonte, A. pintoi BRA-031143 e Pueraria phaseoloides) foram submetidas a quatro níveis de sombreamento artificial $(0 \%, 30 \%, 50 \%$ e $70 \%)$, obtidos com a utilização de telas de polipropileno (sombrite) com, respectivamente, $70 \%, 50 \%$ e $30 \%$ de transmissão de luz. Foi adotado o delineamento experimental de blocos ao acaso, em esquema de parcelas subdivididas e três repetições. As parcelas eram constituídas pelos níveis de sombreamento e, as subparcelas, pelas espécies forrageiras.

As telas foram fixadas em armações de madeira, com $10,0 \times 4,5 \mathrm{~m}$, a uma altura de $2,0 \mathrm{~m}$ acima do solo, para facilitar a circulação de ar e a movimentação sob a cobertura. Nas laterais leste e oeste, as telas foram dispostas em um ângulo de $45^{\circ}$ até $1,0 \mathrm{~m}$ acima do solo, para evitar a penetração do sol pela manhã e a tarde.

As forrageiras foram plantadas em dezembro de 1998, permanecendo sem sombreamento durante 12 semanas, para o pleno estabelecimento. Cada subparcela era constituída por quatro linhas de 2,0 m de comprimento, distanciadas $0,5 \mathrm{~m}$ entre si. A área de amostragem compreendeu as linhas centrais, ficando $0,5 \mathrm{~m}$ em cada extremidade como bordadura, resultando em uma área útil de $1,0 \mathrm{~m}^{2}$.

Em março de 1999, por ocasião da colocação das telas de sombreamento, foi feito um corte de uniformização das parcelas e aplicados, em cobertura, $150 \mathrm{~kg} \mathrm{ha}^{-1}$ de superfosfato simples e $62 \mathrm{~kg} \mathrm{ha}^{-1} \mathrm{de}$ cloreto de potássio, em todas as espécies, e $50 \mathrm{~kg} \mathrm{ha}^{-1}$ 
de uréia nas gramíneas. Em outubro de 1999, realizouse novo corte de uniformização.

As taxas de acúmulo de matéria seca (MS) foram avaliadas por meio de nove cortes, realizados de novembro de 1999 a abril de 2001, sendo seis durante a estação chuvosa (outubro a maio), e três durante a estação seca (junho a setembro). O intervalo entre cortes foi de 5 e 8 semanas nas estações chuvosa e seca, respectivamente. Os capins massai e marandu foram cortados a $20 \mathrm{~cm}$ acima do solo; as demais gramíneas e a puerária, a $10 \mathrm{~cm}$; e os dois genótipos de A. pintoi, a $5 \mathrm{~cm}$. As amostras foram pesadas e secadas em estufa a $65^{\circ} \mathrm{C}$, por 72 horas. As produções de MS obtidas, por corte, foram divididas pelo intervalo entre cortes para o cálculo das taxas de acúmulo de matéria seca.

Os dados de gramíneas e leguminosas foram analisados separadamente. As médias das taxas de acúmulo de MS, referentes aos períodos chuvoso e seco, foram submetidas à análise de variância. As interações significativas foram desdobradas, adequadamente. $\mathrm{O}$ fator qualitativo (gramíneas ou leguminosas) foi submetido à comparação das médias pelo teste de Tukey a 5\% de probabilidade, e o quantitativo (sombreamento), à análise de regressão linear. A melhor equação ajustada foi escolhida de acordo com o coeficiente de determinação e o nível de significância dos coeficientes de regressão.

O grau de tolerância ao sombreamento foi avaliado com base no decréscimo relativo das taxas de acúmulo de MS de cada genótipo, no período chuvoso (valores estimados pelas equações), de acordo com o nível de sombreamento, conforme proposto por Wong (1991).

\section{Resultados e Discussão}

O capim-pensacola apresentou a menor capacidade produtiva entre as gramíneas, principalmente durante o período chuvoso (Tabela 1).

Os capins marandu e massai apresentaram taxas de acúmulo de MS semelhantes, em todos os níveis de sombreamento e épocas do ano, à exceção do tratamento com $30 \%$ de sombra, no período seco, quando o massai obteve menor crescimento (Tabela 1).

No período chuvoso, o quicuio-da-amazônia apresentou taxas de acúmulo de MS semelhantes às dos capins marandu e massai, exceto a $30 \%$ de sombra, quando foi inferior ao capim-marandu, e no maior nível de sombreamento, quando apresentou taxa de acúmulo de MS de apenas 7,0 $\mathrm{kg} \mathrm{ha}^{-1} \mathrm{~d}^{-1}$, três a quatro vezes menor que a dos capins marandu e massai (Tabela 1). Já no período seco, o quicuio-da-amazônia apresentou taxas de acúmulo de MS inferiores às do capim-marandu em todos os níveis de sombreamento, e semelhante às do capim massai apenas nos níveis intermediários de sombreamento.

O quicuio-da-amazônia foi a gramínea que apresentou maior estacionalidade de produção a pleno sol (Tabela 1). Nesta condição, sua taxa de acúmulo de MS no período seco representou apenas $23 \%$ daquela obtida nas águas, enquanto nas demais gramíneas os valores variaram de $51 \%$ a $64 \%$. Alguns estudos têm demonstrado a maior sensibilidade ao estresse hídrico da Brachiaria humidicola em relação a outras espécies do gênero Brachiaria (Mattos, 2001) e a outros gêneros de gramíneas forrageiras (Ruiz et al., 1983).

O sombreamento artificial apresentou efeito indireto, ou seja, amenizou o estresse hídrico durante o período seco e diminuiu a estacionalidade de produção das gramíneas forrageiras. Quanto maior o nível de sombreamento, menor a diferença entre as taxas de acúmulo de MS dos períodos chuvoso e seco; com 70\% de sombra, todas as gramíneas apresentaram maior crescimento no período seco (Tabela 1). Isto se deve às condições climáticas da região, com altas temperaturas e maior insolação (menor nebulosidade) durante o período seco, sendo o crescimento das forrageiras, nesse período, restringido apenas pelo estresse hídrico.

Os capins marandu e massai tiveram comportamento semelhante em relação ao sombreamento no período chuvoso, com as taxas de acúmulo de MS aumentando ligeiramente com $30 \%$ de sombra, e decrescendo suavemente a partir desse nível (Figura 1). Com 50\% e $70 \%$ de sombra, os decréscimos nas taxas de acúmulo de MS do capim-marandu foram de $13 \%$ e $60 \%$, respectivamente, em relação à condição de pleno sol; no capim massai estes decréscimos foram de $17 \%$ e $50 \%$, respectivamente (Figura 2). Estas respostas permitem classificá-las como tolerantes ao sombreamento, confirmando os resultados de outros estudos com a B. brizantha cv. Marandu e com outras cultivares de Panicum maximum (Carvalho et al., 1997; Castro et al., 1999; Andrade et al., 2001a, 2001b).

No período seco, as respostas dos capins marandu e massai ajustaram-se a modelos quadráticos, com as maiores taxas de acúmulo de MS tendo sido verificadas nos níveis intermediários de sombreamento (Figura 1). Estas respostas refletem, em parte, a amenização do estresse hídrico pelo sombreamento artificial. 
O quicuio-da-amazônia mostrou-se relativamente menos tolerante à sombra que as demais gramíneas, embora tenha apresentado bom desempenho sob níveis moderados de sombreamento (até 50\% de sombra) (Figuras 1 e 2). No período chuvoso, os decréscimos em suas taxas de acúmulo de MS a 50\% e 70\% de sombra foram de $25 \%$ e $80 \%$, respectivamente, em relação à condição a pleno sol (Figura 2). Já no período seco, a resposta foi semelhante à do capim-marandu (Figura 1).

Dias-Filho (2002) avaliou as respostas fotossintéticas do capim-marandu e do capim quicuio-da-amazônia sob sombreamento artificial, em casa de vegetação, e verificou que ambas as espécies mostraram-se capazes de ajustar o comportamento fotossintético sob sombreamento, concluindo que o quicuio-da-amazônia seria relativamente mais adaptado ao sombreamento. Tal resultado é contrastante com o obtido neste trabalho e com o de Costa et al. (1998), que compararam a produção de MS destas duas gramíneas sob sombreamento de seringal adulto, em Rondônia, em que a produtividade do capim-marandu foi praticamente o dobro da apresentada pelo quicuio-da-amazônia.

O capim-pensacola confirmou-se como gramínea adaptada a ambientes sombreados, apresentando maior crescimento sob níveis intermediários de sombreamento do que a pleno sol, nas duas épocas, porém de baixa capacidade produtiva (Figura 1). Este fato demonstra que a tolerância ao sombreamento não deve ser o único

Tabela 1. Taxas de acúmulo de matéria seca $\left(\mathrm{kg} \mathrm{ha}^{-1} \mathrm{~d}^{-1}\right)$ de quatro gramíneas e de três leguminosas forrageiras, em função do nível de sombreamento artificial e da época do ano ${ }^{(1)}$.

\begin{tabular}{|c|c|c|c|}
\hline Forrageira & Período chuvoso & Período seco & Taxa de acúmulo $(\%)^{(2)}$ \\
\hline & \multicolumn{3}{|c|}{ Pleno sol } \\
\hline Marandu & $56,1 \mathrm{a}$ & $35,6 \mathrm{a}$ & 64 \\
\hline Massai & $56,3 \mathrm{a}$ & $28,6 a$ & 51 \\
\hline Quicuio-da-amazônia & $54,0 \mathrm{a}$ & $12,4 b$ & 23 \\
\hline Pensacola & $11,0 \mathrm{~b}$ & $6,6 \mathrm{~b}$ & 60 \\
\hline & \multicolumn{3}{|c|}{$30 \%$ de sombra } \\
\hline Marandu & $62,8 \mathrm{a}$ & $51,0 \mathrm{a}$ & 81 \\
\hline Massai & $57,2 \mathrm{ab}$ & $40,1 \mathrm{~b}$ & 70 \\
\hline Quicuio-da-amazônia & $49,2 \mathrm{~b}$ & $30,2 b$ & 61 \\
\hline Pensacola & $13,0 \mathrm{c}$ & $14,7 \mathrm{c}$ & 113 \\
\hline & \multicolumn{3}{|c|}{$50 \%$ de sombra } \\
\hline Marandu & $48,1 \mathrm{a}$ & $48,7 \mathrm{a}$ & 101 \\
\hline Massai & $47,0 \mathrm{a}$ & $34,7 \mathrm{ab}$ & 74 \\
\hline Quicuio-da-amazônia & $45,8 \mathrm{a}$ & $24,3 b$ & 53 \\
\hline Pensacola & $22,9 b$ & $21,7 \mathrm{~b}$ & 95 \\
\hline & \multicolumn{3}{|c|}{$70 \%$ de sombra } \\
\hline Marandu & $22,6 a$ & $31,3 \mathrm{a}$ & 138 \\
\hline Massai & $28,1 \mathrm{a}$ & $32,8 \mathrm{a}$ & 117 \\
\hline Quicuio-da-amazônia & $7,0 \mathrm{~b}$ & $9,1 \mathrm{~b}$ & 130 \\
\hline Pensacola & $9,6 \mathrm{~b}$ & $15,0 \mathrm{~b}$ & 156 \\
\hline & \multicolumn{3}{|c|}{ Pleno sol } \\
\hline Arachis pintoi cv. Belmonte & $59,2 \mathrm{a}$ & $23,0 \mathrm{a}$ & 39 \\
\hline Arachis pintoi BRA-031143 & $41,5 b$ & $23,0 \mathrm{a}$ & 55 \\
\hline Pueraria phaseoloides & $39,3 b$ & $8,8 \mathrm{~b}$ & 22 \\
\hline & \multicolumn{3}{|c|}{$30 \%$ de sombra } \\
\hline Arachis pintoi cv. Belmonte & $53,6 \mathrm{a}$ & $25,5 \mathrm{a}$ & 47 \\
\hline Arachis pintoi BRA-031143 & $30,0 \mathrm{~b}$ & $13,6 \mathrm{ab}$ & 45 \\
\hline Pueraria phaseoloides & $20,1 \mathrm{~b}$ & $11,8 \mathrm{~b}$ & 59 \\
\hline & \multicolumn{3}{|c|}{$50 \%$ de sombra } \\
\hline Arachis pintoi cv. Belmonte & $46,0 \mathrm{a}$ & $22,8 \mathrm{a}$ & 49 \\
\hline Arachis pintoi BRA-031143 & $11,8 \mathrm{c}$ & $10,5 b$ & 89 \\
\hline Pueraria phaseoloides & $20,8 b$ & $10,2 \mathrm{~b}$ & 49 \\
\hline & \multicolumn{3}{|c|}{$70 \%$ de sombra } \\
\hline Arachis pintoi cv. Belmonte & $22,4 \mathrm{a}$ & $3,2 \mathrm{a}$ & 14 \\
\hline Arachis pintoi BRA-031143 & $12,9 \mathrm{a}$ & $3,6 \mathrm{a}$ & 28 \\
\hline Pueraria phaseoloides & $12,6 \mathrm{a}$ & $3,2 \mathrm{a}$ & 26 \\
\hline
\end{tabular}

${ }^{(1)}$ Médias seguidas pelas mesmas letras, na coluna, não diferem entre si pelo teste de Tukey a $5 \%$ de probabilidade. ${ }^{(2)}$ Taxa de acúmulo de MS obtida no período seco, em relação à do período chuvoso. 
critério na escolha de espécies forrageiras para uso em sistemas silvipastoris. Capacidade produtiva, adaptação às condições edafoclimáticas e de manejo, resistência a pragas e doenças, e valor nutritivo também devem ser considerados.

Os capins marandu, massai e quicuio-da-amazônia podem ser utilizados em sistemas silvipastoris na Amazônia Ocidental, sendo o primeiro recomendado apenas para áreas com solos bem drenados e o último, para uso em sistemas com menor densidade arbórea. O capimpensacola não deve ser recomendado para a região, por causa da sua baixa capacidade produtiva.

No período chuvoso, o Arachis pintoi cv. Belmonte foi a leguminosa mais produtiva em todos os níveis de sombreamento, exceto com $70 \%$ de sombra (Tabela 1). Esta leguminosa mostrou-se tão produtiva quanto os capins marandu e massai. Já o acesso BRA-031143 de A. pintoi apresentou taxas de acúmulo de MS semelhantes às da Pueraria phaseoloides nesta época, exceto com 50\% de sombra, quando apresentou menor crescimento. A Pueraria phaseoloides, por causa do seu hábito de crescimento volúvel, com pontos de crescimento pouco protegidos, é uma leguminosa pouco

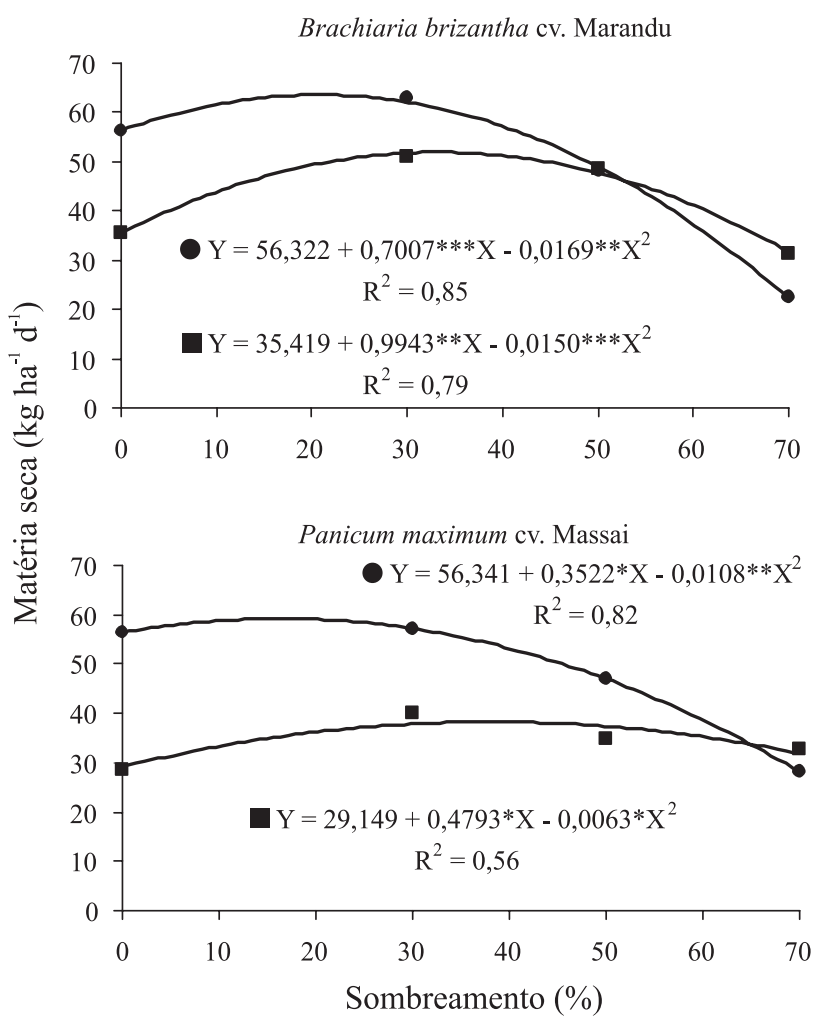

adaptada a regimes de corte, diferente do Arachis pintoi que possui pontos de crescimento rentes ao chão e, portanto, bem protegidos do corte (Pereira, 2001). Assim, é provável que a capacidade produtiva da puerária tenha sido subestimada em relação a situações em que o regime de desfolha é sob pastejo pouco intensivo.

No período seco, os dois genótipos de A. pintoi apresentaram as maiores taxas de acúmulo de MS na condição sem sombra, superando a puerária (Tabela 1). Em níveis intermediários de sombreamento, entretanto, a cultivar Belmonte foi mais produtiva que as demais leguminosas. Já no maior nível de sombreamento, todas as leguminosas apresentaram crescimento muito reduzido neste período.

Os dados referentes à condição a pleno sol indicam que a puerária apresenta menor tolerância ao estresse hídrico que os dois genótipos de amendoim forrageiro, por sua menor capacidade produtiva no período seco e sua maior estacionalidade de produção de forragem taxa de acúmulo de MS no período seco equivalente a apenas $22 \%$ da obtida no período chuvoso (Tabela 1 ).

Nas leguminosas, o efeito indireto do sombreamento artificial, amenizando o estresse hídrico no período seco,
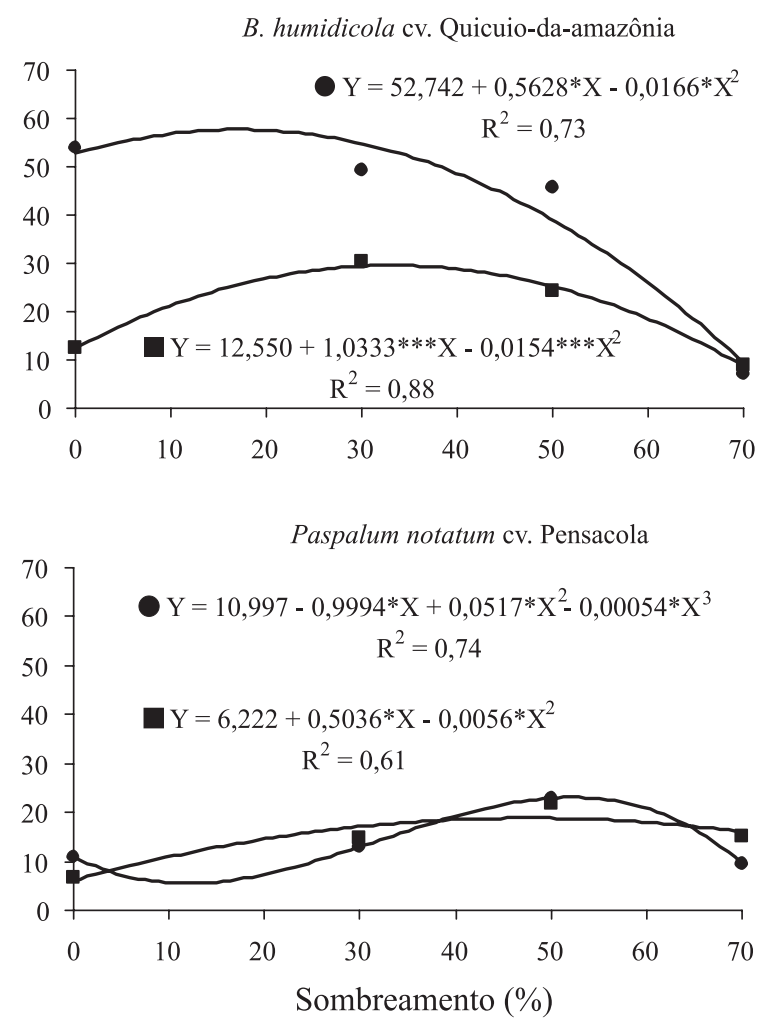

Figura 1. Efeito do sombreamento artificial sobre as taxas de acúmulo de matéria seca de quatro gramíneas forrageiras, nos períodos

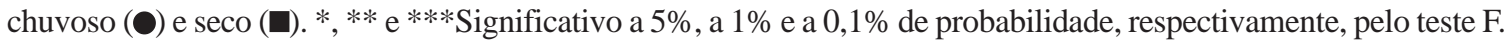


não foi tão marcante quanto o constatado nas gramíneas (Tabela 1).

No período chuvoso, o acesso BRA-031143 e a puerária apresentaram respostas muito parecidas, com as taxas de acúmulo de MS decrescendo linearmente e proporcionalmente ao aumento do nível de sombreamento. Em média, os decréscimos nas taxas de acúmulo de MS destas leguminosas a 30\%, 50\% e 70\% de sombra foram de $31 \%, 51 \%$ e $72 \%$, respectivamente, em relação à condição a pleno sol (Figura 2).

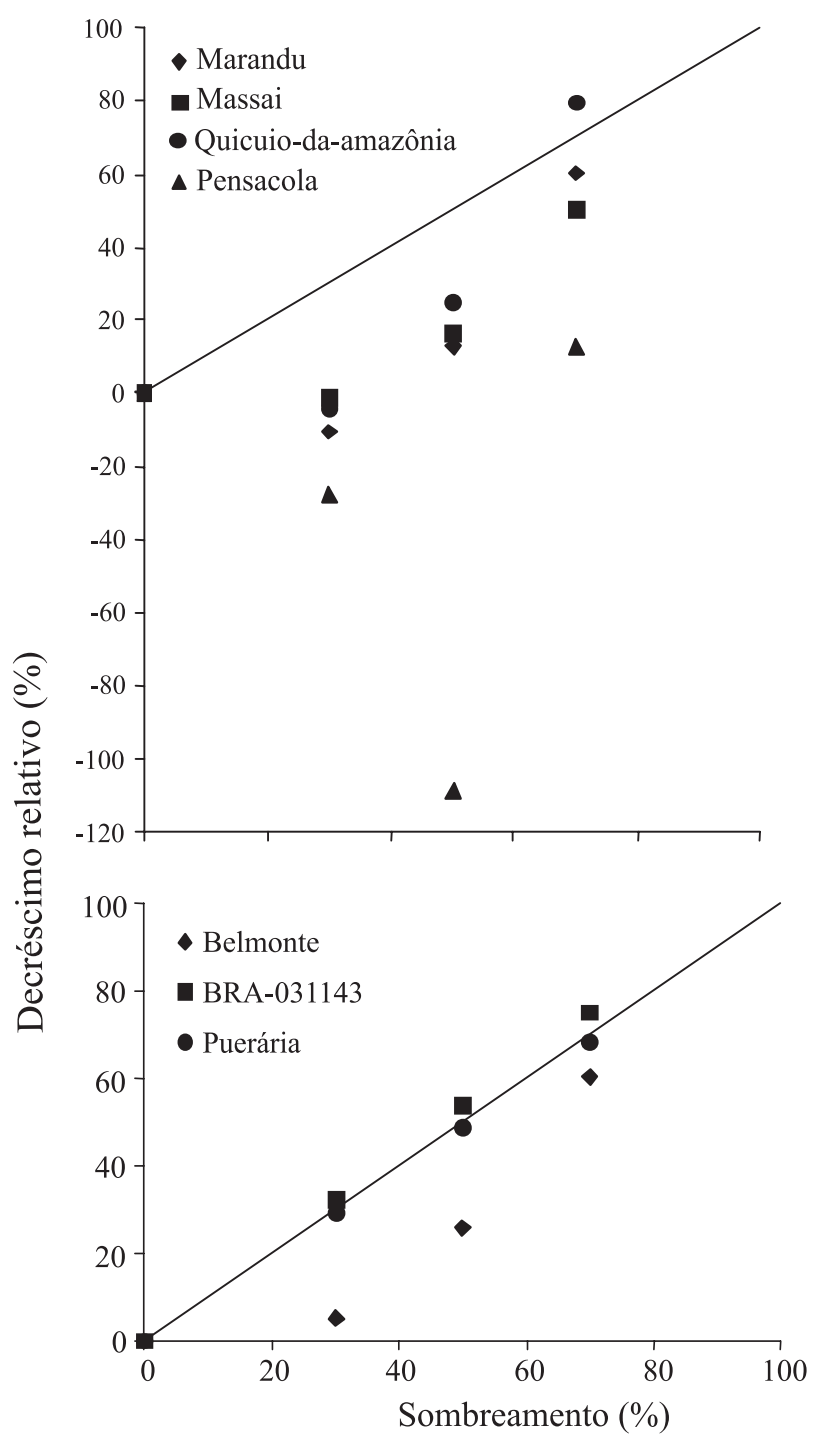

Figura 2. Decréscimo relativo nas taxas de acúmulo de matéria seca de gramíneas e leguminosas forrageiras em função do nível de sombreamento, durante o período chuvoso. A linha transversal representa o decréscimo relativo, sendo proporcional ao aumento do nível de sombreamento.
O comportamento do A. pintoi BRA-031143 foi semelhante ao verificado anteriormente por Andrade \& Valentim (1999), com este mesmo acesso de amendoim forrageiro.

A resposta da cultivar Belmonte ajustou-se a um modelo quadrático, mostrando-se mais tolerante ao sombreamento que as demais leguminosas (Figura 3). Os níveis de sombreamento de $30 \%, 50 \%$ e $70 \%$ causaram redução de 5\%, 26\% e $60 \%$, respectivamente, nas taxas de acúmulo de MS desta leguminosa, em relação à condição a pleno sol (Figura 2). A boa tolerância ao sombreamento é, portanto, um dos fatores que

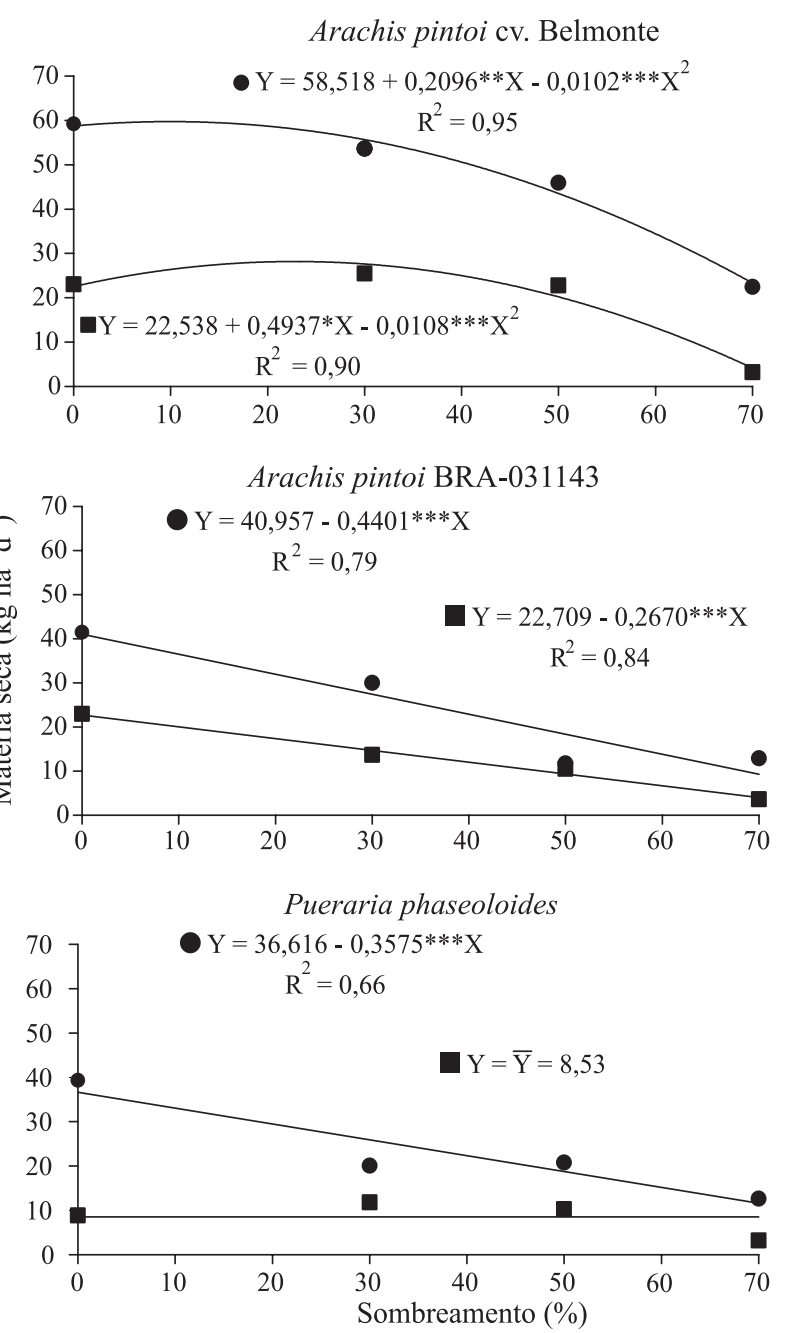

Figura 3. Efeito do sombreamento artificial sobre as taxas de acúmulo de matéria seca de três leguminosas forrageiras, nos períodos chuvoso $(\mathbf{)})$ e seco $(\square)$. *, ** e ***Significativo a $5 \%$, a $1 \%$ e a $0,1 \%$ de probabilidade, respectivamente, pelo teste $\mathrm{F}$. 
explicam a alta capacidade de persistência desta leguminosa, quando consorciada com gramíneas forrageiras (Valentim et al., 2001b).

No período seco, a cultivar Belmonte manteve taxas de acúmulo de MS praticamente estáveis até $50 \%$ de sombra, com queda acentuada no nível de $70 \%$ de sombra (Figura 3). Já o acesso BRA-031143 apresentou queda linear das taxas de acúmulo de MS com o aumento do nível de sombreamento, resposta semelhante à verificada no período chuvoso. $\mathrm{O}$ sombreamento não teve efeito significativo nas taxas de acúmulo de MS da puerária neste período, as quais foram baixas em todos os níveis.

O amendoim forrageiro cultivar Belmonte, que atualmente vem sendo usado na formação de pastos consorciados com gramíneas forrageiras no Acre (Valentim et al., 2001b), demonstrou grande potencial para ser usado em sistemas silvipastoris na Amazônia Ocidental, em virtude de sua alta produtividade de forragem e boa tolerância ao sombreamento. A P. phaseoloides, muito utilizada em toda a Região Amazônica como cultivo de cobertura em plantações de espécies perenes, bem como em pastos consorciados, demonstrou menor tolerância ao sombreamento e ao estresse hídrico que o Belmonte.

$\mathrm{O}$ uso de telas de polipropileno (sombrite) na análise da resposta de plantas ao sombreamento apresenta a vantagem de isolar o efeito da intensidade da radiação fotossinteticamente ativa de outras interferências que ocorrem no sombreamento natural por árvores, tais como a competição por água e nutrientes. Entretanto, esta técnica possui alguns inconvenientes. Um deles é que o sombreamento natural proporcionado por árvores altera tanto a intensidade quanto a qualidade (relação vermelho:vermelho distante) da radiação incidente no sub-bosque (Wilson \& Ludlow, 1991), ao passo que as telas de polipropileno, embora eficientes na redução da intensidade da radiação, não alteram sua qualidade (Huber \& Stuefer, 1997). A redução da relação vermelho:vermelho distante proporcionada pelo sombreamento natural possui importantes efeitos sobre a morfogênese das plantas. Assim, o perfilhamento das gramíneas é mais inibido pelo sombreamento natural do que pelo sombreamento neutro, que não altera a qualidade da luz (Wan \& Sosebee, 1998; Gautier et al., 1999).

O outro inconveniente do sombreamento artificial é que ele altera o microclima do dossel, reduzindo a evapotranspiração (Wilson \& Ludlow, 1991), porém não existe a interferência do componente arbóreo, interceptando a água da chuva em sua copa e competindo com as forrageiras pela água do solo. Nessas condições, há redução do estresse hídrico das plantas sombreadas durante a estação seca, em um nível provavelmente maior do que o proporcionado pelo sombreamento natural.

\section{Conclusões}

1. Os capins marandu e massai apresentam boa tolerância ao sombreamento e alta capacidade produtiva.

2. O capim quicuio-da-amazônia é menos tolerante ao sombreamento e ao déficit hídrico que as demais gramíneas.

3. O capim-pensacola apresenta alta tolerância ao sombreamento, porém baixa capacidade produtiva.

4. O Arachis pintoi cv. Belmonte possui maior capacidade produtiva e tolerância ao sombreamento que as demais leguminosas.

\section{Referências}

ANDRADE, C.M.S.; GARCIA, R.; COUTO, L.; PEREIRA, O.G. Fatores limitantes ao crescimento do capim-tanzânia em um sistema agrossilvipastoril com eucalipto, na região dos cerrados de Minas Gerais. Revista Brasileira de Zootecnia, v.30, p.1178-1185, 2001a.

ANDRADE, C.M.S.; GARCIA, R.; PEREIRA, O.G.; SOUZA, A.L. Desempenho de gramíneas forrageiras e do estilosantes mineirão em sistemas agrossilvipastoris com eucalipto. In: REUNIÃO ANUAL DA SOCIEDADE BRASILEIRA DE ZOOTECNIA, 38., 2001, Piracicaba. Anais. São Paulo: Videolar, 2001b. 4p. CD-ROM - seção forragicultura.

ANDRADE, C.M.S.; VALENTIM, J.F. Adaptação, produtividade e persistência de Arachis pintoi submetido a diferentes níveis de sombreamento. Revista Brasileira de Zootecnia, v.28, p.439-445, 1999.

CARVALHO, M.M.; SILVA, J.L.O.; CAMPOS JUNIOR, B.A. Produção de matéria seca e composição mineral da forragem de seis gramíneas tropicais estabelecidas em um sub-bosque de angicovermelho. Revista Brasileira de Zootecnia, v.26, p.213-218, 1997.

CASTRO, C.R.C.; GARCIA, R.; CARVALHO, M.M.; COUTO, L. Produção forrageira de gramíneas cultivadas sob luminosidade reduzida. Revista Brasileira de Zootecnia, v.28, p.919-927, 1999.

COSTA, N.L.; TOWNSEND, C.R.; MAGALHÃES, J.A.; PEREIRA, R.G.A. Avaliação agronômica de gramíneas forrageiras sob sombreamento de seringal adulto. In: CONGRESSO BRASILEIRO EM SISTEMAS AGROFLORESTAIS, 2., 1998, Belém. Anais. Belém: Embrapa-CPATU, 1998. p.201-203.

DIAS-FILHO, M.B. Photosynthetic light response of the $\mathrm{C}_{4}$ grasses Brachiaria brizantha and $B$. humidicola under shade. Scientia Agricola, v.59, p.65-68, 2002.

DIAS-FILHO, M.B.; CARVALHO, C.J.R. Physiological and morphological responses of Brachiaria spp. to flooding. Pesquisa Agropecuária Brasileira, v.35, p.1959-1966, 2000.

EMBRAPA. Centro de Pesquisa Agroflorestal do Acre (Rio Branco, $\mathrm{AC}$ ). Redução dos impactos ambientais da pecuária de corte no Acre. Rio Branco, 1999. 2p. 
FRANKE, I.L.; LUNZ, A.M.P.; VALENTIM, J.F.; AMARAL, E.F.; MIRANDA, E.M. Situação atual e potencial dos sistemas silvipastoris no Estado do Acre. In: CARVALHO, M.M.; ALVIM, M.J.; CARNEIRO, J.C. (Ed.). Sistemas agroflorestais pecuários: opções de sustentabilidade para áreas tropicais e subtropicais. Juiz de Fora: Embrapa-CNPGL; FAO, 2001. p.19-40.

GARCIA, R.; ANDRADE, C.M.S. Sistemas silvipastoris na Região Sudeste. In: CARVALHO, M.M.; ALVIM, M.J.; CARNEIRO, J.C. (Ed.). Sistemas agroflorestais pecuários: opções de sustentabilidade para áreas tropicais e subtropicais. Juiz de Fora: Embrapa-CNPGL; FAO, 2001. p.173-187.

GAUTIER, H.; VARLET-GRANCHER, C.; HAZARD, L. Tillering responses to the light environment and to defoliation in populations of perennial ryegrass (Lolium perenne L.) selected for contrasting leaf length. Annals of Botany, v.83, p.423-429, 1999.

HUBER, H.; STUEFER, J.F. Shade-induced changes in the branching pattern of a stoloniferous herb: functional response or allometric effect? Oecologia, v.110, p.478-486, 1997.

JOHNSON, S.E.; SOLLENBERGER, L.E.; BENNETT, J.M. Yield and reserve status of rhizoma peanut growing under shade. Crop Science, v.34, p.757-761, 1994.

KARIA, C.T.; ANDRADE, R.P. Cultivo do capim Pojuca. Planaltina: Embrapa-CPAC, 2001. 2p. (Recomendação Técnica, 50).

MATTOS, J.L.S. Avaliações morfofisiológicas de espécies de Brachiaria sob diferentes disponibilidades de água no solo. 2001. 122p. Tese (Doutorado) - Universidade Federal de Viçosa, Viçosa.

PEREIRA, J.M. Produção e persistência de leguminosas em pastagens tropicais. In: SIMPÓSIO DE FORRAGICULTURA E PASTAGENS, 2., 2001, Lavras. Anais. Lavras: UFLA, 2001. p.111142.

PIZARRO, E.A.; RINCÓN, A. Regional experience with forage Arachis in South America. In: KERRIDGE, P.C.; HARDY, B. (Ed.). Biology and agronomy of forage Arachis. Cali: Centro Internacional de Agricultura Tropical, 1994. p.144-157.

RUIZ, M.A.M.; MACHADO, R.C.R.; SOUZA, H.M.F. Produção de quatro gramíneas forrageiras tropicais em condições de deficiência hídrica. Revista da Sociedade Brasileira de Zootecnia, v.12, p.357-369, 1983.
VALENTIM, J.F.; AMARAL, E.F.; MELO, A.W.F. Zoneamento de risco edáfico atual e potencial de morte de pastagens de Brachiaria brizantha no Acre. Rio Branco: Embrapa-CPAF Acre, 2000a. 26p. (Boletim de Pesquisa, 29).

VALENTIM, J.F.; CARNEIRO, J.C.; MOREIRA, P.; JANK, L.; SALES, M.F.L. Capim Massai (Panicum maximum Jacq.): nova forrageira para a diversificação das pastagens no Acre. Rio Branco: Embrapa-CPAF Acre, 2001a. 16p. (Circular Técnica, 41).

VALENTIM, J.F.; CARNEIRO, J.C.; MOREIRA, P.; VAZ, F.A. Capim Pojuca: opção forrageira para os solos de baixa permeabilidade do Acre. Rio Branco: Embrapa-CPAF Acre, 2000b. 4p. (Comunicado Técnico, 114).

VALENTIM, J.F.; CARNEIRO, J.C.; SALES, M.F.L. Amendoim forrageiro cv. Belmonte: leguminosa para a diversificação das pastagens e conservação do solo no Acre. Rio Branco: EmbrapaCPAF Acre, 2001b. 18p. (Circular Técnica, 43).

VALENTIM, J.F.; MOREIRA, P. Produtividade de forragem de gramíneas e leguminosas em pastagens puras e consorciadas no Acre. Rio Branco: Embrapa-CPAF Acre, 2001. 35p. (Boletim de Pesquisa, 33)

WAN, C.; SOSEBEE, R.E. Tillering responses to red:far-red light ratio during different phenological stages in Eragrostis curvula. Environmental and Experimental Botany, v.40, p.247-254, 1998.

WILSON, J.R.; LUDLOW, M.M. The environment and potential growth of herbage under plantations. In: SHELTON, H.M.; STÜR, W.W. (Ed.). Forages for plantation crops. Canberra: Australian Centre for International Agricultural Research, 1991. p.10-24. (ACIAR Proceedings, 32).

WILSON, J.R.; HILL, K.; CAMERON, D.M.; SHELTON, H.M. The growth of Paspalum notatum under the shade of a Eucalyptus grandis plantation canopy or in full sun. Tropical Grasslands, v.24, p.24-28, 1990 .

WONG, G.G. Shade tolerance of tropical forages: a review. In: SHELTON, H.M.; STÜR, W.W. (Ed.). Forages for plantation crops. Canberra: Australian Centre for International Agricultural Research, 1991. p.64-69. (ACIAR Proceedings, 32). 